\title{
ANÁLISE DAS NARRATIVAS DIGITAIS DE PLATAFORMA GAMIFICADA: UMA ABORDAGEM DO DESIGN
}

\section{ANALYSIS OF GAMBLED PLATFORM DIGITAL NARRATIVES: A DESIGN APPROACH}

\author{
Anelise Thaler - UFSC \\ anethaler@gmail.com \\ Francisco Antônio Pereira Fialho - UFSC \\ fapfialho@gmail.com \\ Berenice Santos Gonçalves - UFSC \\ berenice@cce.ufsc.br
}

Palavras-chave: Design de experiência, gamificação, narrativas digitais.

\begin{abstract}
A expansão de oportunidades e informação impactam na nossa cultura e sociedade. Ao mesmo tempo, abrem possibilidades como, combinação de elementos das narrativas digitais para a motivação. Essa motivação, atualmente presente em plataformas gamificadas onde aplica-se mecânicas de jogos e elementos narrativos afim de gerar engajamento e participação por meio da gamificação. Diante do exposto este artigo tem como objetivo identificar os elementos das narrativas digitais orientada pela taxonomia de Nora Paul presentes na plataforma gamificada para a aprendizagem de línguas Duolingo. Como resultado, a pesquisa apresenta a análise dos elementos das narrativas digitais presentes na plataforma Duolingo.
\end{abstract}

Key-words: Experience design, gamication, digital narratives.

The expansion of opportunities and information impact our culture and society. At the same time, they open possibilities as a combination of elements from digital narratives to motivation. This motivation, currently present in gamed platforms where game mechanics and narrative elements are applied in order to generate engagement and participation through gamification. In view of the above, this article aims to identify the elements of digital narratives guided by the taxonomy of Nora Paul present on the computerized platform for learning Duolingo languages. As a result, the research presents the analysis of elements of the digital narratives present in the Duolingo platforms.

\section{Introdução}

Estudos realizados nos últimos anos vêm apresentando as mudanças e o crescimento exponencial das mídias digitais utilizadas por novas gerações. Geração esta chamada pela autora Flora Alves de Millenium uma geração que se envolve, mas precisa perceber que o que faz é relevante, deseja ter feedback constante para saber o seu progresso.

Segundo Alves (2014), o local de trabalho, a sala de aula e o modo como se trabalha mudou. O que funcionava antes não necessariamente funciona hoje quando o assunto é aprendizagem. Cada vez
Realização:
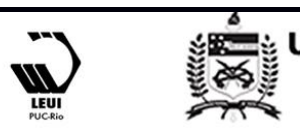


\section{$16^{\circ}$ \\ ERGODESIGN USIHC CINAHPA}

mais a aprendizagem online se apresenta com sua diversidade para responder a distintas culturas, estilos e motivações.

Assim, o presente estudo terá como objetivo analisar os elementos das narrativas digitais presentes na plataforma gamificado Duolingo uma plataforma de ensino de idiomas.

\section{Gamification e experiências de aprendizagem}

A gamificação tem sido observada como "gestão de comportamento" ou como "operador comportamental". O objetivo da aplicação de mecânicas do game design é a condução de um comportamento de usuário previsível desejado. Um dos modelos mais utilizados nos processos de gamificação é o Modelo comportamental de Fogg, que se utiliza de três fatores necessários a qualquer comportamento humano: 1) Motivação, 2)

Habilidade e 3) gatilho. A presença destes três fatores contribui a pessoa agir e realizar a tarefa. Assim, os jogos aumentam a capacidade de percepção dos usuários, tornando trabalhos difíceis mais simples e gerenciáveis, desencadeando a ação desejada a partir do momento que os usuários sentem o desenvolvimento crescente das suas habilidades (TAVERNARI e MURAKAMI, 2014).

De acordo com Prensky (2000), a aprendizagem baseada em jogos deve apresentar as seguintes características: prática e feedback; aprendizagem através do fazer; aprendizagem por meio da tentativa e erro; aprendizagem orientada para objetivos; aprendizagem pela descoberta; aprendizagem guiada; aprendizagem baseada na realização de tarefas; aprendizagem através de questões; aprendizagem situada; representação de papéis; aprendizagem construtivista.

O estilo de aprendizagem pode ser definido como um conjunto de diferentes elementos que o ambiente permite ao indivíduo desenvolver, de acordo com sua preferência. Assim, essa preferência de comportamento consiste de um sistema de regras fundamentadas nas representações mentais dos alunos, no contexto social e de aprendizagem. Entende-se, portanto, $16^{\circ}$ Ergodesign - Congresso Internacional de Ergonomia e Usabilidade de Interfaces Humano Tecnológica: Produto, Informações Ambientes Construídos e Transporte

$16^{\circ}$ USIHC - Congresso Internacional de Ergonomia e Usabilidade de Interfaces Humano Computador

CINAHPA | 2017 - Congresso Internacional de Ambientes Hipermídia para Aprendizagem. que os estilos de aprendizagem definem a forma usual ou a maneira característica que um aluno tem de responder às tarefas de aprendizagem.

\section{Design de Experiência do Usuário.}

User Experience (UX) impacta no design de um sistema, interface, produto ou serviço, seua aspectos determinam como o usuário irá interagir, como se sentirá, bem como as experiências significativas. Ao projetar uma boa experiência o autor Emrah Yayici (2014) apresenta algumas funções:

1) Pesquisa do usuário: fornece uma visão geral do perfil e necessidades do usuário, técnicas como pesquisa etnográfica, definição de persona e modelo mental.

2) Design de interação: com os documentos, necessidades e exigências do perfil do usuário cria-se protótipos de interfaces através dos princípios de design e usabilidade.

3) Arquitetura da Informação: definem as categorias de conteúdo e navegação estrutura da interface, usando técnicas como mapa mental e card-sorting.

4) Usabilidade: avaliação heurística e observações de usuário para encontrar problemas.

As funções colocadas por Emrah Yayici (2014), formam um conjunto de processos e interações para o engajamento do usuário.

Segundo Jesse James Garret (2010), engajamento é o principal objetivo do UX design. "As melhores interfaces de usuário são simples e intuitivas, usuários podem encontrar facilmente o que estão procurando e concluir sua tarefa com eficácia e o mínimo de esforço e erros." (YAYICI, 2014).

Peter Morville apresenta as "sete facetas da experiência do usuário", onde UX é dividido em útil, usável, desejável, encontrável, acessível, confiável e valiosa. Essas facetas se encaixam no modelo de Hassenzahl: útil, utilizável, encontrável, 


\section{$16^{\circ}$ \\ ERGODESIGN USIHC CINAHPA}

$16^{\circ}$ Ergodesign - Congresso Internacional de Ergonomia e Usabilidade de Interfaces Humano Tecnológica: Produto, Informações Ambientes Construídos e Transporte

$16^{\circ}$ USIHC - Congresso Internacional de Ergonomia e Usabilidade de Interfaces Humano Computador

CINAHPA | 2017 - Congresso Internacional de Ambientes Hipermídia para Aprendizagem. credível e acessível, que poderia ser considerada como pragmática (ou seja, utilitária e relacionado à usabilidade), apesar de ser desejável e valioso se qualificaria como hedônica (bem-relacionadaestar) (FREDHEIM, 2011).

O bom UX design além de uma narrativa engloba a performance e eficiência, inteligência e emoção, onde seu propósito está na resolução de problemas e encontrar a melhor maneira de atingir o usuário.

\section{Narrativas digitais}

As novas mídias passam por um período de transição, e as narrativas digitais estão transformando seu conteúdo em uma nova mídia. A narrativa digital, apresenta um caráter multimídia de imagem, texto, som, vídeo e texto, desenvolvido em ferramentas computacionais, que apresentam a possibilidade de publicação e circulação em ambientes virtuais de aprendizagem. Carvalho (2008, p. 88) salienta que:
A construção e produção de narrativas digitais constituem-se num processo de produção textual que assume o carácter contemporâneo dos recursos audiovisuais e tecnológicos capazes de modernizar 'o contar histórias', tornando-se uma ferramenta pedagógica eficiente e motivadora ao aluno, ao mesmo tempo em que agrega à prática docente o viés da inserção da realidade tão cobrada em práticas educativas.

Nora Paul (2010), elaborou uma taxonomia para as narrativas digitais, onde essa pretende auxiliar na criação e na hora de testar a combinação dos elementos usados nas narrativas on-line. Segundo Ferrari (2011), a autora divide os atributos das narrativas digitais em cinco elementos: mídia, ação, contexto, relacionamento e comunicação.

Elemento mídia, refere-se ao tipo de expressão. $\mathrm{O}$ ambiente digital utiliza texto, imagens, gráficos vídeo, áudio e desenho animando. O elemento mídia examina quatro aspectos, (1) Configuração: que se refere a combinação de mídias no desenvolvimento de um conteúdo. (2) Tipo: referese a mídia que está sendo usada, texto, vídeo, áudio. (3) Fluxo: se o conteúdo é assíncrono gravado anteriormente ou síncrono exibindo em tempo real. E (4) Tempo/espaço: refere-se ao conteúdo apresentado em sua totalidade (em tempo real) e o conteúdo previamente editado.

Elemento ação, refere-se a ao movimento e a ação requerida do usuário. A determinação destes dois aspectos se dá na forma dinâmica e na participação ativa do usuário com o conteúdo.

Elemento relacionamento, refere-se ao conteúdo versátil. Ou seja, não-linear, customizável, calculável e expansível.

Elemento contexto, refere-se ao que dá sentido a alguma coisa, e a conteúdos adicionais determinados por sua forma de operacionalização a hipermídia, links embutidos, links paralelos, links internos, links esternos, links suplementares entre outros.

Por fim o elemento comunicação, o que torna o um ambiente digital único, move-se para um ambiente de comunicação tipo um-a-um, ou um-para-vários ou vários-para-um.

\section{Plataforma Gamificada Duolingo}

A plataforma, Duolingo permite o aprendizado de línguas estrangeiras está disponibilizada de forma gratuita na versão online e na versão mobile Android, iOS, Windows Phone e com extensão para o Chrome.

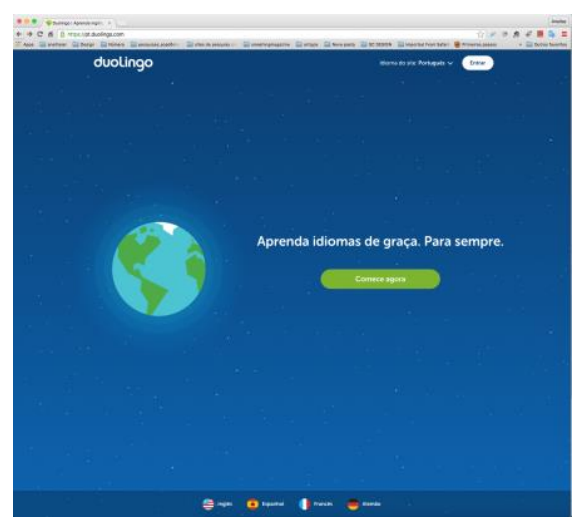

Figura1: apresentação de imagens, texto e gráfico. Fonte: Versão oline Duolingo (2016)

A plataforma apresenta o conteúdo por assuntos 


\section{$16^{\circ}$ \\ ERGODESIGN USIHC CINAHPA}

como saudações, animais, comidas, clima, roupas, cores, família profissões, lugares, objetos, viagem, viagens, números, educação, natureza, esportes, comunicação, artes, medicina, futuro, política e futuro esses são separado em lições disponibilizadas conforme o progresso do usuário, onde desenvolvem habilidades como pronúncia, escrita e compreensão oral.

Para medir o progresso do usuário o sistema gerência a pontuação ao fazer escolhas corretas onde são somados pontos de habilidades ao perfil, que pode personalizar seus dados. A plataforma prevê a motivação dos usuários por meio da interação com outros usuários. Essa interação é possível através do fórum, o usuário pode publicar perguntas para que pessoas mais experientes possam auxiliar.

\subsection{Análise a partir dos 5 elementos das narrativas digitais.}

Através dos cinco elementos da taxonomia de Paul (2010), realizou-se uma análise da plataforma Duolingo apresenta os atributos específicos das narrativas digitais. Essa análise é demonstrada na tabela 1, que apresenta os elementos encontrados na plataforma.

\begin{tabular}{|l|l|}
\hline $\begin{array}{l}\text { ELEMENTOS DAS } \\
\text { NARRATIVAS DIGITAIS }\end{array}$ & ANÁLISE DUOLINGO \\
\hline Mídia & $\begin{array}{l}\text { Conteúdo de mídia } \\
\text { individual e mídia múltipla } \\
\text { com narrativas em } \\
\text { multimídia. }\end{array}$ \\
\hline Ação & $\begin{array}{l}\text { Conteúdo dinâmico, ativo } \\
\text { existem diversas } \\
\text { combinações entre } \\
\text { movimento de conteúdo e } \\
\text { ação do usuário. }\end{array}$ \\
\hline Relacionamento & $\begin{array}{l}\text { Conteúdo calculável e } \\
\text { expansível. }\end{array}$ \\
\hline Contexto & $\begin{array}{l}\text { Narrativa hipermidiática, } \\
\text { links embutidos, links } \\
\text { internos, links } \\
\text { suplementares e Link }\end{array}$ \\
\hline
\end{tabular}

$16^{\circ}$ Ergodesign - Congresso Internacional de Ergonomia e Usabilidade de Interfaces Humano Tecnológica: Produto, Informações Ambientes Construídos e Transporte

$16^{\circ}$ USIHC - Congresso Internacional de Ergonomia e Usabilidade de Interfaces Humano Computador

CINAHPA | 2017 - Congresso Internacional de Ambientes Hipermídia para Aprendizagem.

\begin{tabular}{|l|l|}
\hline & contextual. \\
\hline Comunicação & $\begin{array}{l}\text { Configuração Um-a-Um, } \\
\text { Um-para-Vários do tipo } \\
\text { mensagens para fórum com } \\
\text { direcionamento gravado. }\end{array}$ \\
\hline
\end{tabular}

Tabela 1 - Análise do Duolingo através dos elementos da taxonomia de Nora Paul.

Fonte: o autor (2016)

Elemento 1 Mídia: DUOLINGO apresenta uma mídia do tipo texto, imagens, áudios e gráficos. $\mathrm{O}$ fluxo do conteúdo pode ser considerado assíncrono, entretanto o sistema apresenta uma área de fórum para comunicação entre usuários que pode ser considerada síncrona. No quesito tempo/espaço o conteúdo é apresentado em sua totalidade.

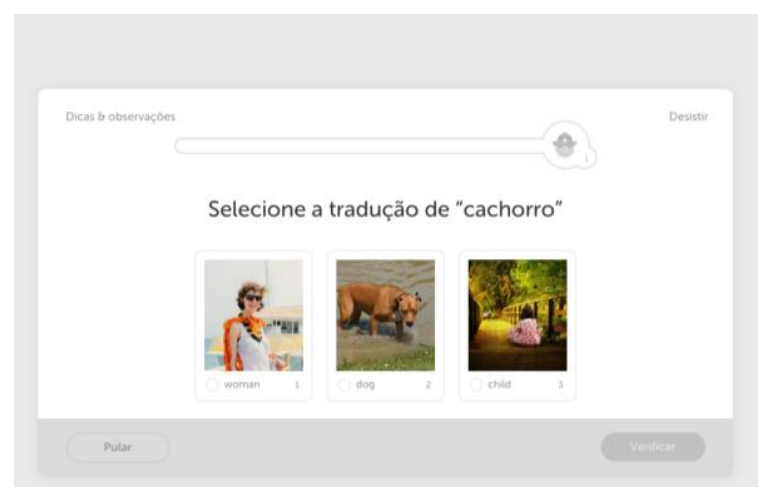

Figura2: apresentação de imagens, texto e gráfico. Fonte: Versão oline Duolingo (2016).

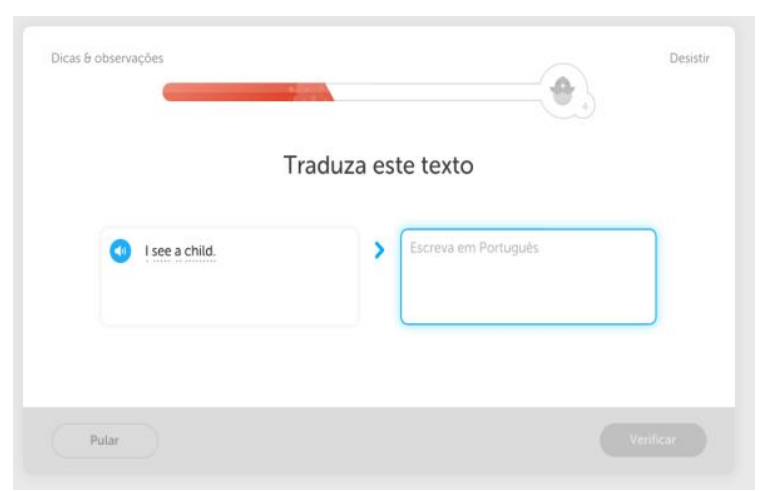

Figura3: apresentação de texto e gráfico. Fonte: Versão oline Duolingo (2016). 


\section{$16^{\circ}$ \\ ERGODESIGN USIHC CINAHPA}

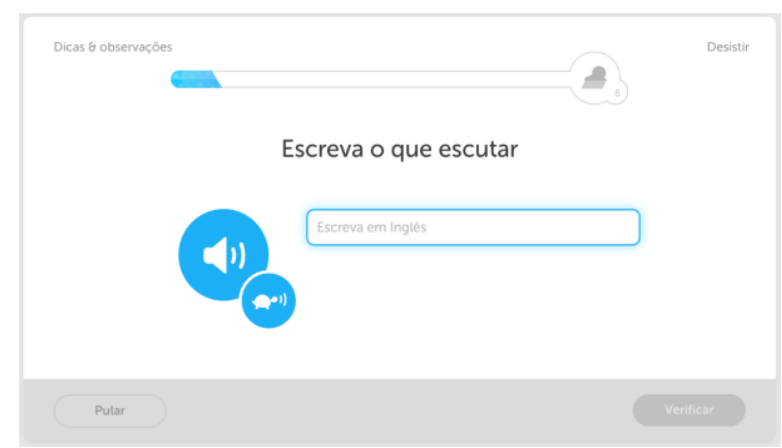

Figura4: apresentação de texto, áudio e gráfico. Fonte: Versão oline Duolingo (2016).

Elemento 2 Ação: Duolingo tem ação dinâmico/passivo o sistema apresenta o conteúdo texto, imagem e áudio em seguida aguarda a intervenção do usuário.

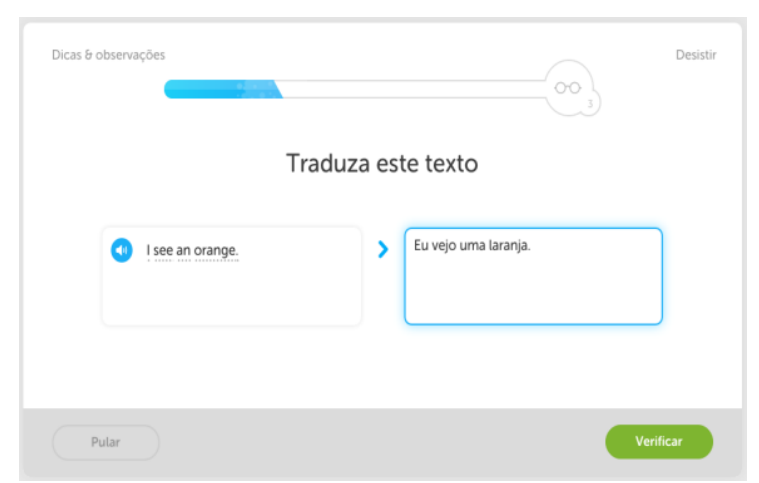

Figura 5: apresentação da intervenção do usuário. Fonte: Versão oline Duolingo (2016)

Elemento 3 Relacionamento: Duolingo possui um conteúdo calculável em cada intervenção o usuário recebe um feedback positivo ou negativo armazenando sua pontuação em casos positivos. O conteúdo é parcialmente expansível oferecendo a possibilidade de o usuário realizar contribuições em materiais adicionais sobre $\mathrm{o}$ assunto $\mathrm{e}$ traduções. $16^{\circ}$ Ergodesign - Congresso Internacional de Ergonomia e Usabilidade de Interfaces Humano Tecnológica: Produto, Informações Ambientes Construídos e Transporte

$16^{\circ}$ USIHC - Congresso Internacional de Ergonomia e Usabilidade de Interfaces Humano Computador

CINAHPA | 2017 - Congresso Internacional de Ambientes Hipermídia para Aprendizagem.

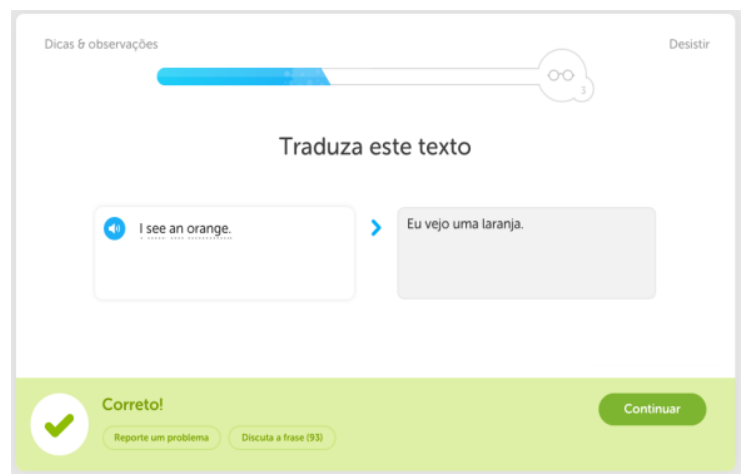

Figura 6: apresentação do feedback positivo. Fonte: Versão oline Duolingo (2016)

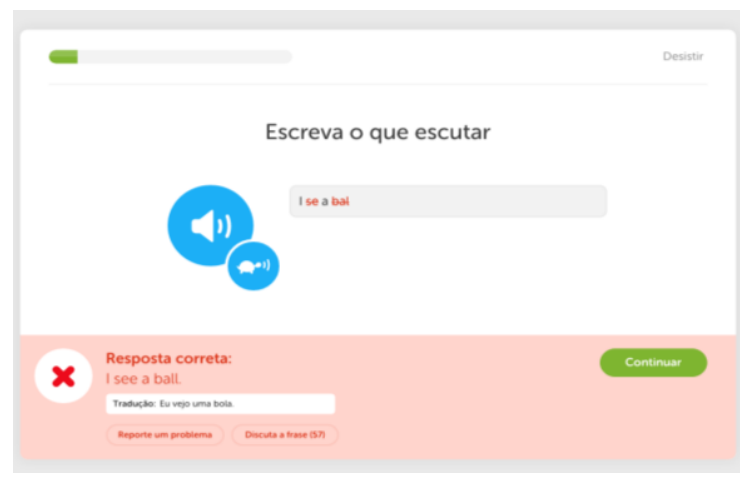

Figura 7: apresentação do feedback negativo. Fonte: Versão oline Duolingo (2016)

Elemento 4: Contexto: Duolindo tem uma narrativa auto-explicativa, inclui links embutidos e paralelo, combinação de links internos e externos tem a possibilidade de incluir conteúdo adicional.

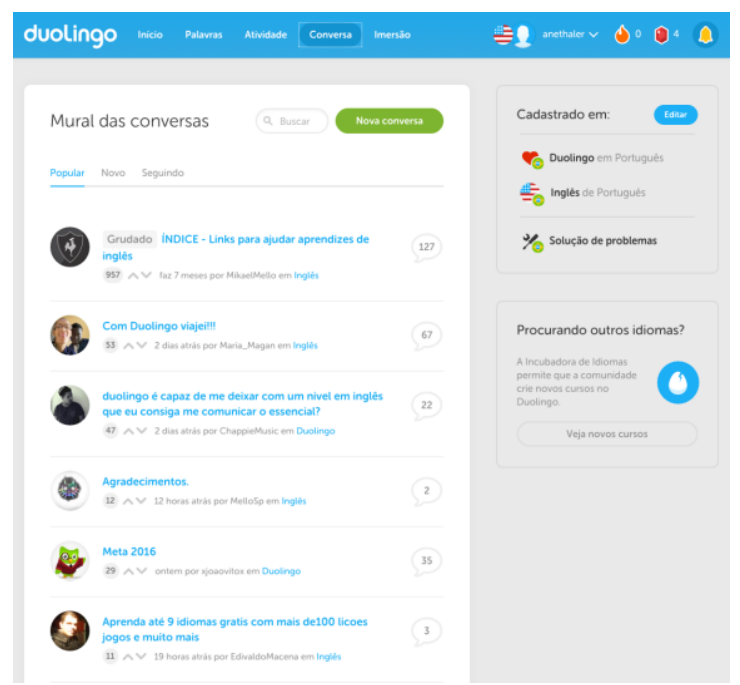

Figura 8: apresentação mural, fórum. Fonte: Versão oline Duolingo (2016) 
$16^{\circ}$ USIHC - Congresso Internacional de Ergonomia e Usabilidade de CINAHPA Interfaces Humano Computador

CINAHPA | 2017 - Congresso Internacional de Ambientes Hipermídia para Aprendizagem.

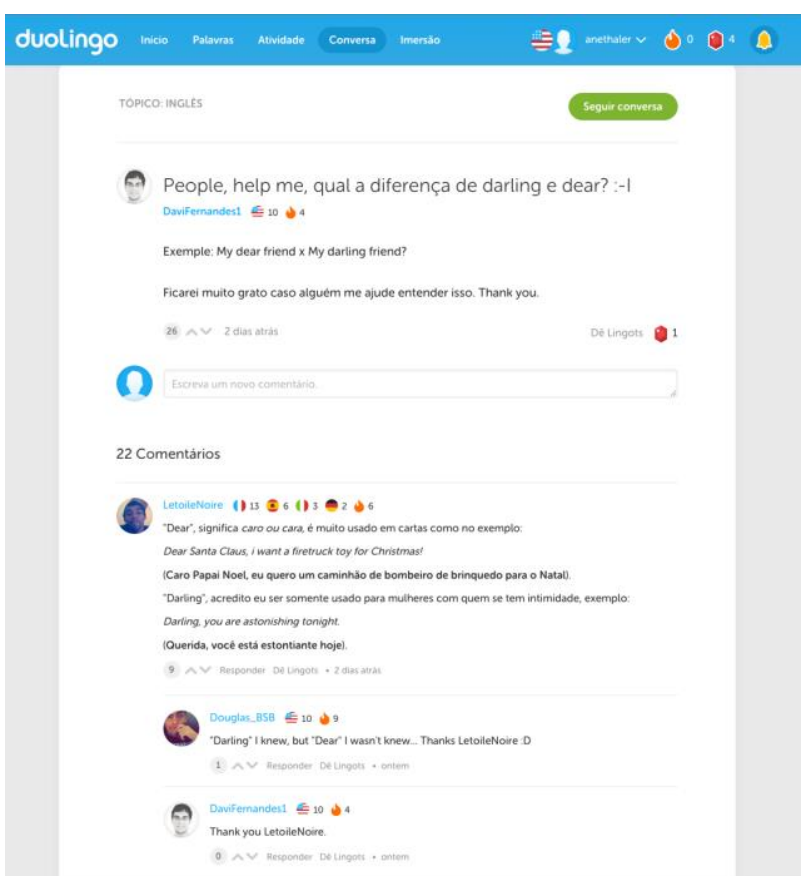

Figura 10: apresentação mural, fórum.

Fonte: Versão oline Duolingo (2016)

Elemento 5 Comunicação: Duolindo tem a habilidade de se conectar com os outros por meio da mídia digital com uma configuração um-a-um, um-para-vários do tipo mensagens para fórum com direcionamento gravado.

\section{Considerações Finais}

User Experience (UX) é um dos aspectos importantes do design de um ambiente virtual e da sua estrutura. Ele determina como o usuário irá interagir, como se sentirá e todas as outras experiências possíveis com o ambiente. UX Design permite facilitar o diálogo entre a audiência, o designer e o objeto a ser projetado. Comece procurando saber sobre o que o usuário realmente deseja.

Os elementos da taxonomia de Nora Paul referente as narrativas digitais são parcialmente utilizadas na plataforma Duolingo. As narrativas digitais, possibilitam a criação de novas soluções e a gamificação engajam de uma forma lúdica e participativa para uma melhor experiência do usuário.

\section{Referências Bibliografias}

ALVES, Flora. Gamification: Como criar experiências de aprendizagem engajadoras. Um guia completo: do conceito à prática. DVS Editora, 2014.

FERRARI, Pollyana. Hipertexto, hipermídia: as novas ferramentas da comunicação digital. Editora Contexto, 2011.

FREDHEIM, Helge. Por experiência do usuário não pode ser concebido. Smashing Magazine. Publicado em mar de 2011. Disponível em: <https://www.smashingmagazine.com/2011/03/wh y-user-experience-cannot-be-designed/ $>$.

GARRET, Jesse James. Elements of user experience, the: user-centered design for the web and beyond. Pearson Education, 2010.

PAUL, Nora. Elementos das narrativas digitais. Hipertexto, hipermídia: as novas ferramentas da comunicação digital. São Paulo: Editora Contexto, p. 121-139, 2007.

TAVERNARI, Mariana; MURAKAMI, Mariane.

Gamificação, estratégias narrativas e experiências do usuário na educação financeira. [en línea]. En: Interaction South America (ISA 14): 6ta. Conferencia Lationamericana de Diseño de Interacción; 2014, nov 19-22; Buenos Aires.

\section{YAYICI, Emrah, UX Design and Usability}

Mentor Book : With Best Practice Business Analysis and User Interface Design Tips and Techniques, 2014.

\section{Agradecimentos}

Agradecimento a Coordenação de Aperfeiçoamento de Pessoal de Nível Superior (Capes) por financiar a pesquisa, Universidade Federal de Santa Catarina (UFSC) pela possibilidade e ao Pós-Design pela a realização da pesquisa. 